\title{
Tourist Writing: Facing and Embracing the Otherness of Space and Narrative
}

NOTE: Due to a possible editorial conflict of interest the author did not participate in the editing/publishing process of this issue of the journal.

\section{Abstract}

This paper sets out to examine a specific body of fictional narratives featuring tourists as protagonists. It is the experience of tourists that determines the plot development, dynamics and denouement of these narratives, and the present paper focuses in particular on Elizabeth Bowen's novel The Hotel (1927) and Tennessee Williams's The Roman Spring of Mrs. Stone (1950). The representation of tourists in fiction contradicts what most theories within tourism study posit, as these fictional tourists are placed outside their comfort zone and, additionally, perceived as individuals, not part of a homogeneous mass. Such placement outside a circumscribed world, as the analysis of the two novels shows, is achieved by heterotopian spatiality which the texts construct, whereby the concept of heterotopia relies on Michel Foucault's writing. The aspect of individuality is stressed through the narrative technique called free indirect discourse; spatiality and narrative combined thus set the scene for representing the experience of tourists. Protagonists in the two novels, Sydney Warren and Karen Stone, embody Dean MacCannell's and Zygmunt Bauman's views of tourists as modern pilgrims, in search of self-discovery through interaction with otherness. Using extracts from both novels, the paper shows how this otherness is constructed spatially, the role narration plays in the process, and the effect it has on tourist protagonists. The analysis results can, finally, be used to advance the academic study of the interconnection between space and narrative in literary fiction and deepen the understanding of tourists' behavior in relation to the particular place in which they find themselves. 
Keywords: Elizabeth Bowen, The Hotel, free indirect discourse, heterotopia, Tennessee Williams, The Roman Spring of Mrs. Stone, tourism

\section{Introduction}

Some travel writers seem to disregard, if not regard with contempt, the very notion of tourists. In an early piece of criticism, Paul Fussell devotes a whole chapter to the distinction between travel and tourism, and the difference that sets both apart from the original concept of exploration. He states that travelers mediate between the two poles, one towards which the explorer gravitates, searching for "the risks of the formless and the unknown," and "the security of pure cliché" towards which the tourist moves (Fussell 40). The traveler, according to Fussell, retains all the excitement of the unpredictable he can, while the tourist strives towards knowing for certain where he is. Even in less formal discourses, the activities pertinent to tourism are usually perceived as mass activities, with very few traces of the individuality that remains the domain of travel. This distinction has been since the publication of Fussell's book (in 1980) critically approached and explained as being "manipulated by the tourist industry to serve its own commercial ends" (Holland and Huggan 2-3). While Romantic authors established "a way of conceiving of a traveller's superiority to tourists" (Buzard, "The Grand Tour" 50) and thus gave rise to the concept of anti-tourism (Buzard, The Beaten Track), in the industry as well as in travel writing, the modern culture of travel in the twentieth century soon started relying precisely on this concept and said superiority of the traveler to market its tourist services. This way it has only been perpetuating the debate and emphasizing the constructed gap between travelers and tourists, with the latter stereotypically represented as those who search for security and the known. The stereotype prevails even in some of the more practically oriented theories within tourism studies - in the thesis, for example, that "the tourist is placed at the centre of a strictly circumscribed world" where actors such as travel agents or hotel managers serve as surrogate parents, who "relieve the tourist of responsibility and protect him/her from harsh reality." (Urry 7)

This paper proposes a different approach, claiming that a body of literary texts written throughout the twentieth century, and focusing on the experience of tourism, stresses the individuality of tourists placing them outside the borders of the circumscribed world they should be inhabiting while 
on holiday. These texts include novels such as Elizabeth von Arnim's The Enchanted April (1922), Elizabeth Bowen's The Hotel (1927), Tennessee Williams's The Roman Spring of Mrs. Stone (1950), Ian McEwan's The Comfort of Strangers (1981), or Anita Brookner's Hotel du Lac (1984). The fact that the protagonists of these novels are tourists is what determines the plot development, dynamics, and denouement of the narrative, and the protagonists' status of tourists is most pronounced through their interaction with the surrounding space and places. The mentioned novels do not fall within the scope of the strictest definition of travel writing, not because they describe tourists instead of travelers, but rather because they are in entirety works of fiction: they do not present accounts of real journeys and are not narrated in the first person ${ }^{[1]}$ They rely largely on the use of the narrative technique known as free indirect discourse (FID), which entered the world of literary fiction with modernist authors and has remained its prominent feature ever since. It is a feature that implies a sort of "otherness" in relation to both first- and third-person narration; the experience of otherness is, what is more, inherent in the literary representations of tourists' perception of space. While standard travel writing deals with "a movement through space" (Thompson 9), tourist writing - the designation we might tentatively use ${ }^{[2]}$ - deals more with the arrival, or rather stay, with being, for however brief a period of time, part of the foreign, different, other space. In a similar vein, whereas "the impetus of travel is essentially utopian" (Ashcroft 249), the impetus to experience foreign space as a tourist is essentially heterotopian.

\section{Placing Tourists in Fiction}

The focus of the present analysis is on Elizabeth Bowen's first and Tennessee Williams's only novel, The Hotel and The Roman Spring of Mrs. Stone, respectively. These novels are chosen from the listed body of tourist writing for the simple reason that they show the variety offered to tourists in terms of the place they visit; they feature two distinctive kinds of places for tourists (a seaside resort and an urban area). Despite the generic difference between these places, the experience of the tourist protagonists is rather similar (and this should also be the case in Von Arnim's, McEwan's, and Brookner's novels as well as similar texts). The Hotel centers around a group of British holiday-makers spending winter in a hotel on the Italian Riviera in the 1920s. The nameless hotel does not merely function as a literary device by which Bowen gathers a group of 
strangers together - it is a force that influences their behavior and provides both impetus and comfort for, among others, the protagonist, Sydney Warren. Inspired by Bowen's stay in Bodrighera, Italy, and a broken engagement (Glendinning 40), The Hotel deals primarily with young Sydney's doubts about her future, a fragile friendship she develops with Mrs. Kerr, her sudden decision to marry a clergyman, James Milton - a new guest at the hotel - and equally sudden resolution to end the engagement. The Roman Spring of Mrs. Stone similarly details several months in the life of a very rich American widow, former actress now faced with advancing age and left rootless - drifting - after her husband's death. She seems to be in search of love in Rome, but her affair with Paolo, a handsome young gigolo she dotes on, ends tragically. Karen Stone insists on avoiding the hordes of other American tourists in post-war Rome: she stays at first at the Hotel Excelsior, but there she is "harassed by too frequent meetings with acquaintances among the tide of American tourists and movie people" and so decides to take the apartment "which stood like the solitary eyrie of a bird above the roofs of the city." (Williams 36) The decision and the corresponding description indicate that Karen Stone wishes not only to merge with the locals and experience the community from the inside, but also that she claims a vantage point for herself, from which she can have a commanding view over the entire stage that the city of Rome becomes for her. This puts forward the questions of tourist motivation, namely, of what drives people - in the present case, the fictional tourists Sydney Warren and Karen Stone - to visit particular places and what kind of experience they are looking for there.

One of the ways in which tourists can be perceived is as modern pilgrims (MacCannell; Bauman). Intrinsic to this perception is a quest for authenticity, which is sought for in "other 'times' and other 'places' away from that person's everyday life" (Urry 9). The authenticity here discussed is not an external factor, related to the genuineness of the lived experience or visited place. Rather, it is internally motivated as a form of self-discovery. This self-discovery "through a complex and sometimes arduous search for an Absolute Other" is, according to MacCannell, "a basic theme of our civilization," which has throughout centuries developed from the proper activity of a hero, through the activities of a group such as the Crusaders, and entire social classes in the case of the British Grand Tour concept, to the universal experience of every person, which is best seen in the activities of tourists (5) ${ }^{[3]}$ Tourists are, it transpires, in search of themselves; this is the case with 
the protagonists of the two novels. Sydney Warren's vacation abroad with her cousin Tessa appears to be "an inspired solution of the Sydney problem" (Bowen 20) - the problem of Sydney being on the verge of a breakdown, having passed many exams and wondering about what she would do during the following year. Vacation abroad seems to be the ideal solution, as "Sydney could be out of doors all day long; she might distinguish herself in tennis tournaments; she might get engaged." (Bowen 20) It is, in other words, an excellent opportunity for a girl in her early twenties to fulfil the expected social role - excel in public activities such as tennis or dances and eventually get married. Sydney in the end proves unready for these expectations and decides to organize her future in accordance with her own wishes instead, which is probably the most legitimate instance of self-discovery. Karen Stone in Williams's novel experiences a continual state of drifting, not being bound to a particular time or place, and she yearns to stop the drift. This, in her view, she achieves by forming a union with the "other" - Paolo first, then, after Paolo leaves her, with a mysterious young man who has been following her around Rome all the time. Karen Stone's search for an Absolute Other is based on love, which, in the words of Alain Badiou, has "the quest for truth about difference" as its main function (72). Experiencing love is, like any selfdiscovery, based on finding oneself from the other side of the mirror, through the experience of the other. This otherness inherent in self-discovery, in the search for individuality, is spatially contextualized due to the simple fact that the protagonists in both novels are tourists. And, if the experience of otherness needs to be discussed in terms of spatiality, the perfect - if not the only possible - framework is offered by Michel Foucault's concept of heterotopias.

In the same way that tourists are modern pilgrims and tourism "a form of sacred experience" (Graburn 24), heterotopias are places that in the modern world preserve the aura and significance of sacred localities. Unlike utopias, heterotopias exist as real localities in which "all the other real sites that can be found within the culture, are simultaneously represented, contested, and inverted." (Foucault 24) They appear in two basic, historically conditioned forms: as crisis heterotopias and heterotopias of deviation, the former being "privileged or sacred or forbidden places, reserved for individuals who are, in relation to society and to the human environment in which they live, in a state of crisis: adolescents, menstruating women, pregnant women, the elderly, etc." (Foucault 24) Even a superficial look at the two protagonists reveals that they are in a 
critical period of their lives: the above mentioned "Sydney problem" indicates that; moreover, Sydney feels "anxious to precipitate a crisis" (Bowen 30). Karen Stone exhibits symptoms of the approaching old age crisis, keeping a plastic surgeon card, which she hides from herself even, artfully applying make-up even during casual walks, and generally feeling, after the abandonment of her career, her husband's death, and the beginning of menopause, that she is "leading an almost posthumous existence" (Williams 36). Moreover, other tourists in The Hotel also seem to be in states of more or less explicated crises, for example, Sydney's cousin Tessa, who suffers from a still unidentified complaint (Bowen 19), or Mrs. and Miss Pinkerton, who remark on the similarity between being abroad and being ill (Bowen 29), as both states indicate exclusion from society, or a critical situation that is better dealt with some place other than the normal place of residence. The hotel itself, as a form of temporary home away from home, is heterotopian in its essence; for Karen Stone, the entire Rome assumes heterotopian qualities: as she goes out on the street, having just been betrayed by Paolo, and stands "in the amethyst light of prima sera," the feeling is the same as if she were illuminated with a spotlight (Williams 94). The city becomes a theatre, which is one of the forms heterotopias can take (Foucault 25). Heterotopias, as this paper goes on to expound, are described in both novels as bearing the transformative potential for tourists, which is necessary for their quest, but also as narrative constructs created by the protagonists themselves. The spatial otherness is in terms of the narrative related to the strategy of FID, the application of which signals both the construction of heterotopia and a crucial moment in the development of characters' individuality.

\section{Narrative Framework}

FID and the advance of mass travel seem to be products of the same age: facilitated movement and newly developed means of transportation quite possibly marked modernity as much as the narrative technique in question marked modernism as the corresponding literary movement. FID is a hybrid form which combines verbal tenses and pronouns from indirect discourse with the tone and order of the sentence from direct discourse, thus also forming a mixture of narrative distance and emotional approach (Moretti 81). This hybridity indicates, as all authors who have researched narrative and stylistic elements of FID agree, a polyvocal, dialogical, or metatextual nature of 
writing (Rimmon-Kenan 117-19; Nørgaard, Montoro, and Busse 90), to the effect that its very use in a text becomes a marker of the text's literariness (Leskiv 53; Banfield 68; Rimmon-Kenan 118). Furthermore, Franco Moretti stresses the extra-textual quality of FID, describing the technique as a specific "third voice of the well-socialized individual" (Moretti 82), which contributes to social mediation between the text and its readers. It is this quality that has gained prominence within the study of literary tourism: this "imperceptible discourse that is attributed to no-one" creates space in the literary text for the inscription of the emotions, opinions, and observations that are consumed by readers in the process of their socialization (Mansfield 71$)^{[4]}$ While this socializing aspect of FID will be referred to in the concluding part, what is of interest for the analysis of tourist in fiction is the general connection between FID and fictional space or, more precisely, the inherent ability of FID to create a heterotopian setting. FID appears, in the words of Franco Moretti, a form in which characters "speak of themselves in the third person, as if from the outside" (82). This mode of narration, as described by Moretti, evokes the mirror image of a character - the combination of the personal and the impersonal creates "the voice of the reflection" effect, an imaginary situation in which one's mirror image might speak of the person in front of the mirror. The mirror is, according to Foucault, a perfect example of heterotopia because it exists in real space, where "it exerts a sort of counteraction on the position" the person in front of it occupies (24). It provides an inversion of the person's appearance, which has the potential to reveal the truth hidden beneath this appearance: starting from the gaze directed by the mirror image, from its virtual space, one comes back towards oneself, beginning to reconstitute oneself where they are (Foucault 24). In The Hotel and The Roman Spring of Mrs. Stone, as the analysis will show, the use of FID serves to produce the mirror effect (not necessarily using the symbolism of the mirror), or the quality of otherness in the surrounding space, with a view to reconstituting the position of the tourist protagonists in terms of their search for self-discovery. The search is continually contextualized within the status of protagonists (and other characters) as tourists: it is the displacement from their ordinary surroundings (Sydney's home in England and Karen Stone's in America) that allows them to venture out into the otherness or sacredness of particular newly discovered places and, following the encounter with otherness and a process of self-reflection, potentially reconstitute their ordinary, "homely" selves. 


\section{The Ultimate Riviera}

The heterotopian qualities of the Hotel in Bowen's novel are stressed by its frequent (explicit or implicit) comparisons to home, whereby it becomes the other, inverted home for its residents. Even those who have not spent much time at the Hotel feel the place in this way - because Hotel time, as James Milton remarks, is reckoned differently (Bowen 126). This somewhat distorted image of a hotel as home is reinforced by the equally distorted identification of (adult) characters as children. Another reference to Milton indicates that he "still had a childish pleasure in arriving at places at night, as though he had been brought there blindfolded" (Bowen 32), whereby the time of arrival endows the place with an additional measure of otherness. Mrs. Kerr's son Ronald is, too, described in terms of a child who has arrived at the Hotel in search of his mother. Having been in Germany for some time, he was there overwhelmed with "a childish feeling of homelessness" (Bowen 108), so meeting his mother at the Hotel becomes also the arrival home. The interconnection between heterotopia (the Hotel as an inversion of home) and FID in narration becomes clearer in the following longer excerpt:

Round him stripes prevailed, on the tight brocades of the upholstery, on the mats methodically diamond-wise on the polish; stripes were repeated innumerably in the satiny wallpaper and the lace blinds over the door. One had a sense of being caged into this crowded emptiness. This seemed the strangest place to sit and make demands on motherhood, the strangest place for motherhood, answering, to make itself palpable. He felt impelled to ask his mother some fantastic question: "What do I mean to you?" or "What part do I play in your life?" or even (a final outrage), "Do you care for me?" (This he could not remember that she had ever avowed.) (Bowen 108)

The unique mixture of the third-person narration and personal voice is marked by the use of "this" in "This seemed" instead of "that" (Rimmon-Kenan 114-16), expressions of emotions and memory, which are stressed even graphically, with the use of brackets, and the description of Ronald's immediate surroundings, that is, of what Ronald sees, in the first sentence (Leskiv). The stripes he sees evoke to Ronald the impression that he is encaged, whereby the vast hotel lounge becomes, in accordance with Foucault's description of heterotopia, a place where several incompatible sites are juxtaposed (Foucault 25). The very fact that a single place contains numerous inscriptions and 
countless possibilities, that it is a theatre-like setting where different stories can unfold and evolve, enables Ronald to pose "fantastic" questions, albeit in his mind only, about his relationship with his mother.

There is also, of course, the protagonist, Sydney Warren, the ultimate child. It is of some importance that Sydney is, like many more women characters in Bowen's other novels, most likely an orphan. Consequently, perhaps, she becomes overly attached to Ronald's mother. The friendship between the two women of so noticeably different age seems to be an attempt on Sydney's behalf to find a mother-substitute - or family-substitute, for that matter. The desire not to feel homeless is further developed in her relationship with James Milton. Like Ronald, Milton is somewhat disoriented by the place; he also similarly constructs it in terms of heterotopia:

He suffered, as he did at last confess to himself, and began to wonder why he had ever left his parish, where the crippling sensitiveness of his childhood had at least been deadened by the activity of every day, and where in the assured retreat of office he had had no need to ask what he was. But the place was beautiful and completely satisfied him once he had been able to reconcile what he saw with what he had imagined, and to recognize that while an ultimate Riviera could only have existence in the mind of God, this was as fair an imitation as it was reasonable to expect.

(Bowen 72-73)

The first sentence in the excerpt serves to introduce Milton's thoughts in the form of FID, as he "began to wonder" about his vulnerability, which is exposed now he is on vacation. The second sentence provides his view of the Riviera, the most perfectly conceivable image of the paradisiacal place, which again relates the Riviera to heterotopia, to the effect that it contains the quality of a sacred place among the set of ordinary, everyday locations. For Milton, this sacredness is, above all, revealed through beautiful vistas of the coast. In other words, it is again what one sees that reveals this heterotopian quality: it is in those places which "are chosen to be gazed upon because there is anticipation, especially through daydreaming and fantasy, of intense pleasures" (Urry 3) that tourists' interaction with the otherness of space begins, and it is from their encounter with such places that they can embark on radical life changes. Milton proposes to Sydney suddenly surprising even himself - while they are sitting on a plateau overlooking the sea, with beautiful views of the coast and high hills further behind in the countryside. Sydney does not seem to be 
equally impressed with the view, and she rejects Milton immediately; it is only during her subsequent visit to a cemetery that she reconsiders her decision. Cemetery may indeed seem like an awkward place to consider marriage proposals, but it is one of the prime examples of heterotopias - "the other city" according to Foucault (25), which hosts the souls of all those who are now "outside" - and, therefore, the place which allows for difference-making decisions to be made. Located in the vicinity of the Hotel, the cemetery serves as its mirror image. Cordelia, the little girl who accompanies Sydney on her walk with Milton to the plateau, and then to the cemetery, remarks that people in hotels are hardly alive and, additionally, that people only exist when they matter - when they are terribly in love, or in danger (Bowen 93). The meaning of her words - that being in love is being alive, staying at the hotel gradually deadening - strikes Sydney at the cemetery. She already feels betrayed at this point by Mrs. Kerr's intensive relationship with her son, which appears to be detrimental to the friendship between the two women. Sydney gradually realizes that Mrs. Kerr has snubbed her, leaving with Ronald, and the snub acquires the proportions of abandonment - the family and home substitutes she has found in Mrs. Kerr and the Hotel prove insufficient. The detailed description of the graveyard, as Sydney and Cordelia peer through its gates, presents it as quite an opposite of what a cemetery should be: "[e]verywhere, in ribbons, marbles, porcelains was a suggestion of the salon," which makes Cordelia remark that Italian graves "look so much more lived in," upon which Sydney suddenly pushes the gate open and enters the cemetery (Bowen 99). The act is an expression of her desire to feel alive, but in the same way that Ronald feels encaged in the salon-like setting of the lounge, she soon starts feeling entrapped among the graves - precisely because of the life she reads into them, which she feels she lacks. This is, again, narratively expressed as FID: "Once among the graves she stood with Cordelia behind her, looking round again. She was oppressed by the thought, less of death than of the treachery of a future that must give one to this ultimately" (Bowen 99) - "this" instead of "that" appearing (again) as the marker of FID and referring to what she in fact sees. Her thoughts lead towards the revelation that she has not invested into her own future, whereas Milton's proposal was an act of investment, and hence noble. And, as these thoughts evolve, the text switches sentences between the third person and the socially mediating "third voice," which again reveals the heterotopian juxtaposition of all things imaginable: "They went on to look at the English end of 
the cemetery ... How complete the Riviera was, thought Sydney, one could even die here" (Bowen 102).

Sydney's decision to accept Milton's proposal follows this visit to the cemetery; the problem is, however, in her mistaken assumption that she could make heterotopia permanent, that is, make the Hotel her home by relating Milton's proposal to this, as she states, "improbable place" (Bowen $168)$ - it is equally impossible as making Mrs. Kerr her mother. Sydney can create a different space using her thoughts, and her tourist gaze, but she cannot create a home. She realizes this, indeed, and the rejection of this mistaken assumption presents her finally as a real tourist. Ending her engagement to Milton, she moves away to another place on the French Riviera before returning to England. She realizes that, as regards home and homesickness, one cannot invest into the future, at least not in the present tourist state, where the value of home "lies precisely in its tendency to stay in the future tense forever" and not be formed within the present (Bauman 30). While yearning to return home, tourists are also afraid of being home-bound, as home for them represents "an uncanny mix of shelter and prison" (Bauman 31), which is what Sydney experiences at the cemetery and initially fails to grasp, but finally understands. This understanding, ending the engagement, and leaving for another hotel make her story an accolade of the tourist in the then incipient industry of mass tourism.

\section{Town Three Thousand Years Old}

The gap between being homesick and home-bound is equally important for Karen Stone in Tennessee Williams's novella. While she seemingly wishes to form a new home in Rome, she in effect recreates the "extended tourist escapade" that Bauman speaks of, whereby "tourist conduct becomes the mode of life" for her (30). Her American friend Meg Bishop judges this kind of conduct as escapism and weakness (Williams 17); Karen Stone, however, refers to it as drifting. As one of the earliest established categories of (non-institutionalized, non-mass) tourist, the drifter is the type who ventures furthest into the unknown of a foreign place, aiming to achieve a complete immersion into the host culture. Drifters "are conceived as generally being children of affluence on a prolonged break from middle-class responsibility," which - even though the term nowadays refers mostly to backpacker, lifestyle, and similar (usually marginal) forms of tourism (Cohen 271) - 
corresponds to Karen Stone's stay in Rome. The antiquity of the city is often stressed in the text, whereby it serves as a mirror reflection of Mrs. Stone's age. Meg Bishop juxtaposes the two, "the crumbling golden antiquity of the city beneath" and "the ageing and frightened face of the woman beside" (Williams 18). Mrs. Stone's selection of the location for her Roman abode - the highest floor of a palazzo next to the Spanish stairs, whose terrace gives her a panoramic view of the domes of churches, "swelling above the angular roofs like the breasts of recumbent giant women" (Williams 9), and where she looks, as the text frequently stresses, like a bird of prey - is her way of harnessing and conquering the individual process of ageing. One way of conquering the city is through engagement with the locals. As a gigolo, a marchetta, young Paolo is part of the market made for tourists and the rich - a market that, in one form or another, persists to this day in urban surroundings. Mrs. Stone, however, is not interested in trading: her interest lies simply in experiencing the otherness, whether of foreign people such as Paolo (she keeps avoiding Americans in Rome as much as she can) or foreign places (whereby the "conquering" of Rome implies the acquisition of the dignity Rome's antiquity possesses, which could also endow her own forthcoming old age with dignity). What impresses her about Rome is in fact the illusionary youthfulness of the city:

To Mrs. Stone the city itself appeared to be performing some leisurely trick of levitation. Each spring morning when she came out on her terrace, the intricately-woven and gold-dusted web of the streets, in which the domed churches stood like weaving spiders, seemed to have lost more gravity, to be floating gradually, weightlessly upward into the blue-gold warmth of the days, all serenity, all buoyancy, and making no effort. Such a thing is possible only in a youthful condition which Mrs. Stone had now passed. (Williams 52)

Youthfulness is the impression that only she among the novella's characters has: it is her thoughts expressed in FID by means of somewhat broken syntax ("all serenity, all buoyancy") and in the even more explicitly personal interior monologue, marked by the present tense of "is," which emphasizes the preceding use of FID. Even before such a bright view, she soon lapses into anxiety and a feeling that something bad will happen, and this presentiment is also expressed when she looks at herself in the mirror: 
She dashed the tepid water in her face. She made a gasping sound, but all of these expressions of violent feeling seemed to have no association with anything that happened in her head. Her head was remarkably quiet, as if a savage bird had been locked in it which had now flown out through some invisible opening. No. It was not necessary to take the sedative which she had thoughtlessly reached for. She set it down in the cabinet and closed the door which became her face in a mirror, and she saw the face looking at her, somewhat curiously, somewhat uneasily, and as she looked at it, a flush spread over the face as if she had surprised it in doing something that it was ashamed

$$
\text { of... }
$$

The drift! (Williams 19-20; emphasis added)

FID appears with the comparison of Karen Stone's thoughts to a savage bird (the comparison that, however frequently it appears in the novel, is only made in this form of the third voice) and, more explicitly, with the elliptical negative sentence and decision not to take the sedative (emphasized above) - an action only she could have been aware of intending to perform. FID also opens the way for a heterotopian representation of Karen Stone through her mirror image, which leads towards the affirmation of her drifter tourist state. However, this mirror heterotopia causes uneasiness, similar to the one Karen Stone feels when gazing at the streets and domes of Rome beneath her terrace. Her answer to the uneasiness is the drift - an activity one cannot feel ashamed of because it does not have a reason or purpose (Williams 20). The state of drifting is contrasted with the state of heterotopia: Paolo, the foreigner, belongs in Mrs. Stone's view to the former as the relationship with him is one of the possible ways to stop the drift. Furthermore, while the drift does not have purpose, it does have direction (Williams 39), and this direction that she tries to stop with Paolo is towards the old age. As a tourist, therefore, she shows that even the socalled drifters also feel, however suppressed the feeling may be, the need for a purpose, and the desire to locate a "different space" which might lead towards their self-discovery.

This self-discovery comes in the present case in the form of harsh reality. The anxiety Mrs. Stone feels in front of the mirror is revealed gradually, as she witnesses "that her face in the mirror had not weathered the critical period just passed through so triumphantly as had the organs that kept her living. Her body had flown like a powerful bird through and above the entangling branches of 
the past few years, but her face now exhibited the record of the flight." (Williams 87-88) The feeling is expressed, again, in the form of FID, signaled grammatically, for instance, by the use of "now" instead of "then" (italicized). Moreover, it is not only the mirror that reveals the advance of the old age, but the city too: as she applies make-up that is almost as professional as the one she used to wear on the stage, she realizes that it is not sufficient since "Roman sunlight was not in sympathy with the deceit" (Williams 88). Namely, operating as any heterotopia does, both the mirror and the city, as spaces of illusion, expose every other real space as still more illusory (Foucault 27). This, in the case of Mrs. Stone, is the space she occupies in front of the mirror, and her attempts to deceive the future with make-up are exposed as a subterfuge. Similarly, the otherness embodied in Paolo's foreignness and youth finally shows the indignity of the age gap between them (Hooper 161) instead of the dignity Mrs. Stone had tried to assume in Rome, as Paolo publicly humiliates her. However, like Sydney, Karen Stone also provides an appraisal for the rising community of drifter tourists: as soon as Paolo leaves her, she invites to her apartment the young man who has been following her around Rome. In this way, she sustains both Rome's sexual economy (Hooper 117) and the tourism market, by admitting that stopping the drift can be arranged by what this market offers. Additionally, as suggested by Hooper (164), she achieves an even deeper immersion into the host culture since the new young man in her life appears to be homeless, a dweller of the streets of Rome, and thus perhaps, if gradation of any kind should be allowed for, more Roman than Paolo.

\section{Conclusion}

The above provided examples from the two novels merely present a selection of textual references to heterotopias, expressed in FID and related to tourist protagonists and characters. Both The Hotel and The Roman Spring of Mrs. Stone abound in similar examples, and so do the other novels mentioned in the introductory section. It seems that mass tourism, as one of the most influential social phenomena of the 20th century, has inspired a solid body of fiction, which also reflects the changes and various aspects of the industry. Regardless of whether the setting is urban or rural, it is, in all the works of tourist fiction, heterotopian. The otherness of space serves to stress the experience of tourists, whose activities are not criticized as pernicious to the 
environment but rather praised as a form of the search for self-discovery, a sacred act of pilgrimage in a world otherwise devoid of sanctity. The otherness of space is accompanied by the narrative strategy of FID, which enriches these texts with literariness. As a discourse that provides a point of view different from that of either characters or the narrator, FID occupies a space in which the reader too can participate: belonging to no one in particular, utterances in FID acquire the status of authority and the power to draw the limits of experience (Mansfield 53) - in the present case, tourists' experience. In other words, FID provides implicit instruction in motivation and behavior of tourists and potentially also guidelines for the tourist's appreciation of space. This it achieves by pointing out to how space is constructed as heterotopian and participating actively in its narrative construction. The analyzed examples, in this respect, show how particular locations (such as the hotel salon, the graveyard, the balcony or any plateau with a view) in the place where a tourist temporarily stays inspire the tourist's considerations of home, the sense of orientation, or future prospects - in other words, many of the issues that aid or enable the process of selfdiscovery, which takes place in relation to the specific state of being displaced - the state of being a tourist.

By way of conclusion, it would perhaps be more useful to point out some possible directions which further academic study of fiction about tourists might take. The fact that protagonists in all the mentioned novels are women should be taken into consideration. The opportunities of travel which opened up with modernity were especially relevant to women, who had historically been more restricted to home than men. Fiction about tourists presents, in a way, a fictional history of women as tourists. This in turn also calls for additional consideration of gendered spaces, and perhaps more particularly, the role of FID in constructing gendered spaces as one of the numerous facets of the complex and undeniably important connection between space and narrative.

\section{Works Cited}

Ashcroft, Bill. "Travel and Utopia." New Directions in Travel Writing Studies, edited by Paul Smethurst and Julia Kuehn, Palgrave, 2015, pp. 249-62.

Banfield, Ann. Unspeakable Sentences: Narration and Representation in the Language of Fiction. Routledge \& Kegan Paul, 2015. 
Badiou, Alain. In Praise of Love. Serpent's Tail, 2012.

Bauman, Zygmunt. "From Pilgrim to Tourist - or a Short History of Identity." Questions of Cultural Identity, edited by Stuart Hall and Paul du Gay, Sage Publications Ltd., 1996, pp. 18-36.

Borm, Jan. "Defining Travel: On the Travel Book, Travel Writing and Terminology." Perspectives on Travel Writing, edited by Glenn Hooper and Tim Youngs, Ashgate Publishing, 2004, pp.13-26.

Bowen, Elizabeth. The Hotel. 1927. University of Chicago Press, 2012.

Buzard, James. The Beaten Track: European Tourism, Literature, and the Ways to "Culture", 1800-1918. Oxford University Press, 1993.

Buzard, James. "The Grand Tour and After (1660-1840)." The Cambridge Companion to Travel Writing, edited by Peter Hulme and Tim Youngs, Cambridge University Press, 2002, pp. 37-52.

Cohen, Scott A. "Drifter." Encyclopedia of Tourism, edited by Jafar Jafari and Honggen Xiao, Springer International Publishing, 2016, pp. 271-72.

Foucault, Michel. "Of Other Spaces." Diacritics, vol. 16, no. 1, 1986, pp. 22-27.

Fussell, Paul. Abroad: British Literary Traveling Between the Wars. Oxford University Press, 1980. Glendinning, Victoria. Elizabeth Bowen: Portrait of a Writer. Penguin Books, 1985.

Graburn, Nelson H.H. "Tourism: The Sacred Journey." Hosts and Guests: The Anthropology of Tourism, edited by Valene L. Smith, University of Pennsylvania Press, 1989, pp. 21-36.

Holland, Patrick, and Graham Huggan. Tourists with Typewriters: Critical Reflections on Contemporary Travel Writing. The University of Michigan Press, 2000.

Hooper, Michael S.D. Sexual Politics in the Work of Tennessee Williams. Cambridge University Press, 2012.

Leskiv, Alina. "The Literary Phenomenon of Free Indirect Speech." Seria Filologiczna Studia Anglica Resoviensia, vol. 6, no. 60, 2009, pp. 51-58.

MacCannell, Dean. The Tourist: A New Theory of the Leisure Class. University of California Press, 1999. 
Mansfield, Charlie. Researching Literary Tourism. University of Plymouth, PEARL, 2015.

Moretti, Franco. Graphs, Maps, Trees: Abstract Models for a Literary History. Verso, 2007.

Nørgaard, Nina, Rocío Montoro, and Beatrix Busse. Key Terms in Stylistics. Continuum International Publishing Group, 2010.

Rimmon-Kenan, Shlomith. Narrative Fiction. Routledge Taylor \& Francis Group, 2005.

Thompson, Carl. Travel Writing. Routledge, 2011.

Williams, Tennessee. The Roman Spring of Mrs. Stone. 1950. Grafton Books, 1977.

Urry, John. The Tourist Gaze: Leisure and Travel in Contemporary Societies. Sage Publications Ltd., 2002. 
[1] By way of explanation, it would be useful to refer here to some of the definitions of travel writing. In line with his strict distinction between travelers and tourists, Paul Fussell also differentiates among guidebooks, travel books, and exploration/discovery accounts, contrasting them all with the novel. His idea of travel books implies that "travel books profess to be a representation of a journey, and of events on that journey, that really took place" (Thompson 15) - they have a literary dimension and serve an esthetic purpose but are primarily non-fictional. Jan Borm accepts Fussell's definition of travel books but differentiates them from travel writing, which he defines as "a collective term for a variety of texts both fictional and non-fictional whose main theme is travel" (13). The definition allows for the inclusion into travel writing of novels such as Joseph Conrad's Heart of Darkness, Herman Melville's Moby-Dick; or, The Whale, or Laurence Sterne's A Sentimental Journey through France and Italy, but they also allow for the inclusion of practically any text as "there are few literary texts that do not make some reference to travel, and/or offer some representation of movement through space" (Thompson 24). A somewhat compromising definition of travel writing is given by Holland and Huggan, who see (most) travel narratives as "fictions of factual representation" (10).

[2] Bearing in mind the given definitions of travel writing and the listed corpus of tourist writing, the following definition of the latter might be offered: an entirely fictional account, using the third-person narrative with abundant reliance on free indirect discourse, which represents tourists - styled as such (and not "travelers") due to the fact that tourist writing belongs largely to the twentieth century, that is, the era which saw the rise of the tourist industry - only for the duration of their stay in a foreign place, which proves to be formative to the tourist character/protagonist.

[3] It is obvious, though still worth stressing, that MacCannell's view of tourists is by no means disparaging (perhaps because his approach is from within tourism studies, unlike Fussell's, whose basis is travel writing) - the same goes for sociologist Zygmunt Bauman and anthropologist Nelson H. Graburn.

[4] While literary tourism is not in itself the subject of this paper, further research might be directed towards examining the extent to which tourist writing is suitable as the basis for developing literary tourism. No tours seem to exist in either Bodrighera, which inspired The Hotel, or Rome, based on 
The Roman Spring of Mrs. Stone. With FID being the narrative feature that makes a text particularly prone to successful literary tourism (Mansfield), this potential of the two novels, as well as other similar writings, remains to be further developed within tourist industry.

\section{(c) $($ ) (3)}

Creative Commons Attribution-NonCommercial-NoDerivatives 4.0 International License 